\title{
Low Cost, Easy Scalable High Entropy Alloy (HEA) FeCoNiZnGa for High-Efficiency Oxygen Evolution Reaction (OER)
}

Lalita Sharma ${ }^{1}$, Nirmal Kumar ${ }^{2,3}$, Rakes Das ${ }^{4}$, Khushu Tiwari ${ }^{4}$, C.S. Tiwary ${ }^{4 \#}$, Krishanu Biswas $^{1 \#}$, A. Halder ${ }^{1 \#}$

${ }^{I}$ School of Basic Sciences, Advanced Materials Research Centre (AMRC), Indian Institute of Technology Mandi (H.P), Kamand, Mandi - 175005, INDIA

${ }^{2}$ Department of Materials Science and Engineering, Indian Institute of Technology Kanpur, Kanpur-208016 INDIA

${ }^{3}$ School of Engineering, London South Bank University, 103 Borough Road, London, SE10 AA, UK

${ }^{4}$ Metallurgical and Materials Engineering, Indian Institute of Technology Kharagpur, Kharagpur-382355, INDIA

\begin{abstract}
Oxygen evolution reaction (OER) is the key step involved both in water splitting devices as well as in rechargeable metal-air batteries and there is an urgent requirement for a highly stable and low-cost material for efficient OER. In this article, for the first time, electrocatalyst based on high entropy alloy (HEA) of FeCoNiZnGa has been reported for OER. Nanocrystalline high entropy alloys materials withdrew the attention of the research academia due to their emerging unique properties due to the cocktail effect and synergetic effect between the constituent elements. The existing materials $\left(\mathrm{IrO}_{2}, \mathrm{RuO}_{2}\right.$, etc.) being utilized in the OER reaction contain precious metals. Thus, high entropy alloy made up of low-cost elements has been formulated and tested for the OER, which is found to be highly stable and more efficient. The formulation of nanocrystalline HEA (FeCoNiZnGa) utilized a unique recipe casting-cum-comminution (CCC). After electrochemical $\mathrm{CV}$ activation, transition metal oxides formation at the HEA surface helps in OER activities. HEA exhibits a low overpotential of $370 \mathrm{mV}$ to achieve a current density of $10 \mathrm{~mA} \mathrm{~cm}{ }^{-2}$ with a very small Tafel slope of $71 \mathrm{mV} \mathrm{dec}^{-1}$ and exceptional long term stability of electrolysis for over $10 \mathrm{~h}$ in $1 \mathrm{M}$ $\mathrm{KOH}$ alkaline solution, which is extremely stable in comparison to the state-of-the-art OER electrocatalyst $\mathrm{RuO}_{2}$. Transmission electron microscopic (TEM) studies after $10 \mathrm{~h}$ of long term chronoamperometry testing confirmed high stability of HEA as no change in the crystal structure observed. Our work highlights the great potential of HEA towards oxygen evolution reaction which is primary reaction involved in water splitting.
\end{abstract}

Keywords: High entropy alloy; Oxygen evolution reaction; electrocatalyst, electron microscopy, sustainable energy. 


\section{Introduction}

The modern era is devoted to hunt for alternative avenues of sustainable energy or alternative for fossil fuels, which must be environmentally acceptable ${ }^{1}$. Electrochemical water splitting is viewed as one of the simplest and environmental approaches because of its sustainability and environmental friendly behaviour ${ }^{2-3}$. Electrocatalytic oxidation of water to oxygen $\left(\mathrm{O}_{2}\right)$ by oxygen evolution reaction (OER) is one of the major roadblocks for the storage of electricity from renewable sources in the form of molecular fuels like $\mathrm{H}_{2}$ or hydrocarbons ${ }^{4-5}$. Water splitting efficiency is limited due to the higher overpotential offered in anodic OER $\left[4 \mathrm{OH}^{-} \rightarrow 2 \mathrm{H}_{2} \mathrm{O}+\mathrm{O}_{2}+4 e^{-}\right]$, which involves migration of 4 electrons ${ }^{6-7}$ Great efforts have been put forward in exploring the robust electrocatalyst for OER. Noble metal-based electrocatalyst $\mathrm{IrO}_{2}$ and $\mathrm{RuO}_{2}$ are very much active with benchmarking activity for OER with more practical applications. ${ }^{8}$ However, scarcity and high cost of noble metal-based electrocatalyst restrict its large scale applications. Hence, it is the utmost need to develop a non-noble metal-based electrocatalyst to increase the overall efficiency of water splitting and which further permits its applications in broader fields. Recently, a lot of efforts have been devoted to synthesize the transition metal-based alloys ${ }^{9}$, arbides $^{10}$, borides $^{11}$, and sulphides ${ }^{12}$ as an effective electrocatalyst for OER ${ }^{13}$. Therefore, research efforts are devoted to develop low-cost new materials and enhance their efficiency and stability using different strategies. ${ }^{14-}$ 15 Nanocrystalline high entropy alloys (HEAs) hold a promising way of tuning their efficiency and durability by different compositions. The high entropy alloy materials are multi-element, single-phase materials holding the "cocktail" and "synergetic" effect of different metal atoms ${ }^{16-18}$. 
From the last past decade, numerous reports have been published for HEA for electrochemical activities due to its unique properties. ${ }^{19-20}$ HEAs in a simple solid solution have been studied as multifunctional materials by tuning their thermal, electrical, magnetic, and catalytic properties. The HEAs are a solid solution of four or five principle elements with unique properties such as simple solid-solution phases (face-centered cubic, body-centered cubic, and hexagonal closed-packed), lattice distortion ${ }^{21}$, slow diffusion, phase stability, etc. It is noteworthy that most HEAs reported so far contain active transition metals ${ }^{22}$ such as $\mathrm{Ni}$, $\mathrm{Co}$, and Fe, which are commonly used for electrochemical catalysis; however, to the best of our knowledge, the research on HEAs for electrocatalysis is not much explored. Till now, HEA has been explored in various electrochemical activities as $\mathrm{CO}_{2}$ reduction ${ }^{23}$, for $\mathrm{OER}^{6}$, for $\mathrm{HER}^{24}$ (hydrogen evolution reaction) due to its unique properties ${ }^{25}$. Our previous studies have found $\mathrm{AgAuPtPdCu}$ alloys having exceptional electrochemical catalyst properties ${ }^{26-28}$. Nevertheless, this alloy having precious metals, and thus we have designed a new recipe utilizing low-cost metal atoms such as $\mathrm{Fe}, \mathrm{Co}, \mathrm{Ni}, \mathrm{Zn}$, and $\mathrm{Ga}$ metals. The equiatomic composition nanocrystalline HEA alloy FeCoNiZnGa was synthesized using novel strategies casting-cum-comminution $(\mathrm{CCC})^{29}$. These techniques are easily scalable and cost-effective and also provide surface nanoparticles, which are highly desirable for catalytic activity.

To the best of our knowledge, there is no report about electrochemical OER based on the newly synthesized FeCoNiZnGa HEA. Herein, for the first time, we report the promising OER activities in comparison to the noble metal-based electrocatalyst. Electrochemical testing indicates that FeCoNiZnGa HEA as a working electrode exhibits low overpotential with a very small Tafel slope with excellent stability and durability, which is comparable or even better than that of some presently reported catalysts and also state-of-the-art $\mathrm{RuO}_{2}$ catalyst. The experimental investigation provides evidence for the benefit from the oxidation of FeCoNiZnGa HEA powders during the electrochemical CV-activation process. The 
findings reported in this article will surely inspire the other researchers to explore more HEA as functional materials.

\section{Experimental Section}

The pure metals Fe, Co, Ni, Zn, Ga were purchased from Alfa Aesar with 99.99\% purity. $\mathrm{KOH}$ was purchased from Hi-Media laboratories. Nafion (5\%) solution is used as a binder in making the catalyst ink.

Casting-cum-comminution: In this technique, all metals in equi-atomic proportions have been melted in a vacuum arc melting furnace and cast as an ingot. The prepared ingot was melted in the furnace 2-3 times to achieve chemical homogeneity. Afterward, the casted ingot was vacuum sealed in the quartz tube and homogenized at $1000{ }^{\circ} \mathrm{C} / 10 \mathrm{hr}$. After that the ingot has been parted into small pieces for mechanical milling at extremely low temperature utilizing liquid nitrogen as a coolant to achieve the nanocrystalline HEA for 6 hours.

\section{Materials Characterization}

The UV-visible spectrometer (Thermo Scientific, UK) was utilized to record the surface plasmon resonance peak of nanocrystalline HEA. The Panalytical XPert empyrean makes PANalytical was used to study the crystallographic phase using X-rays $(\mathrm{Cu} k \alpha \lambda=1.54046$ $\mathrm{nm})$. The particle size, elemental mapping, and their morphologies were investigated using a Transmission electron microscope (FEI, Titan $\mathrm{G}^{2} 60$ operated at $300 \mathrm{kV}$ ). X-ray photoelectron spectroscopy (XPS) was used to know about the chemical states of the elements by using Nexsa instrument (Thermo Fisher Scientific) incorporating Al Ka as a source of X-ray. Electrochemical measurements have been performed by using Metrohm, Autolab electrochemical workstation. 


\section{Electrochemical measurements:}

Electrochemical measurements have been performed in a three-electrode set-up with Metrohm, Autolab electrochemical workstation. The $5 \mathrm{~mm}$ GCE (glassy carbon electrode) modified with catalyst ink utilized as a working electrode, Pt wire utilized as the counter electrode, and $\mathrm{Ag} / \mathrm{AgCl}$ is used as a reference electrode. $1 \mathrm{M} \mathrm{KOH}$ (potassium hydroxide) is used as an electrolyte, which is used after inert $\mathrm{N}_{2}$ gas saturation for 30 minutes prior to experiments. All experiments have been carried out with $\mathrm{Ag} / \mathrm{AgCl}$ as a reference electrode,

which is converted to RHE by using the equation $E_{R H E}=E_{\text {exp. }}+0.059 p H+E_{A g / A g C l}^{0}$, where $E_{A g / A g C l}^{0}=0.19 \mathrm{~V}$ is the standard reduction potential of $\mathrm{Ag} / \mathrm{AgCl}$ at room temperature, and the $\mathrm{pH}$ of the medium is alkaline. The catalyst ink was made by mixing 10 mg of catalyst in $500 \mu \mathrm{l}$ of DMF (dimethylformamide) solvent and $20 \mu \mathrm{l}$ of Nafion solution (5\%) as binder followed by sonication. The $10 \mu \mathrm{l}$ of catalyst ink was drop casted on the $5 \mathrm{~mm}$ diameter of GCE with a catalyst loading of $0.981 \mathrm{mg} \mathrm{cm}^{-2}$, respectively.

The OER testing is performed in $1 \mathrm{M} \mathrm{KOH}$ electrolyte. Linear scan voltammetry (LSV) was performed with a scan rate of $5 \mathrm{mV} / \mathrm{sec}$. Cyclic voltammetry $(\mathrm{CV})$ activation scans were conducted in a potential window of $0.48 \mathrm{~V}$ to $1.50 \mathrm{~V}$ vs RHE at a scan rate of $50 \mathrm{mV} / \mathrm{sec}$. A cyclic durability test was performed in the potential window from $1.21 \mathrm{~V}$ to $1.56 \mathrm{~V}$ vs RHE at a scan rate of $50 \mathrm{mV} / \mathrm{sec}$ upto $6000 \mathrm{CV}$ cycles. The Tafel plots were plotted by taking the linear region of polarization curves, which were fitted in accordance with Butler-Volmer equation $(\eta=b \log j+a$, where $j$ is current density, $b$ is Tafel slope, a is the intercept) to find out the mechanism of reaction.

\section{Results and Discussion}

The high entropy alloy materials are mostly prepared by vacuum arc melting, which is an easy and scalable process for retaining the purity or decided stoichiometric proportion of 
metallic elements. Further, the preparation of nanocrystalline HEA utilizing mechanical milling at extremely low temperatures makes it an easy, cost-effective technique because extremely low temperature accelerates the fracture process, and also the nanoparticles are in the form of pure virgin surface, which is highly desirable for catalytic activity ${ }^{29-31}$. The nanocrystalline FeCoNiZnGa crystallographic phase has been estimated using an X-ray diffraction pattern, and it is face-centered cubic (FCC), as shown in Figure 1a. The nanocrystalline HEA average particle size $8 \pm 4 \mathrm{~nm}$ estimated using around 500 particles from a bright-field TEM image, as shown in Figure 1c. It also possesses the nanocrystalline ring diffraction FCC pattern, as shown in Figure 1d. The particles are having a native surface or free from an oxide layer or contamination, as shown in high-resolution TEM image Figure 1e. The FFT filtered image of HRTEM has shown in Figure 1f marked d-spacing (111) 0.202 $\mathrm{nm}$, which has also been corroborated with the X-ray diffraction pattern. Figure $1 \mathrm{~g}$ shows the elemental mapping of a single HEA nanoparticle, which proved the nanoparticles are chemically homogenous. The metallic nanocrystalline materials show the surface plasmon resonance phenomena on the exposure of electromagnetic radiation, which appeared for FeCoNiZnGa at $262 \mathrm{~nm}$, as shown in Figure 1b. Therefore, the nanocrystalline FeCoNiZnGa is a suitable candidate for the electrochemical catalyst materials as it having a pure surface and chemically homogeneous. 

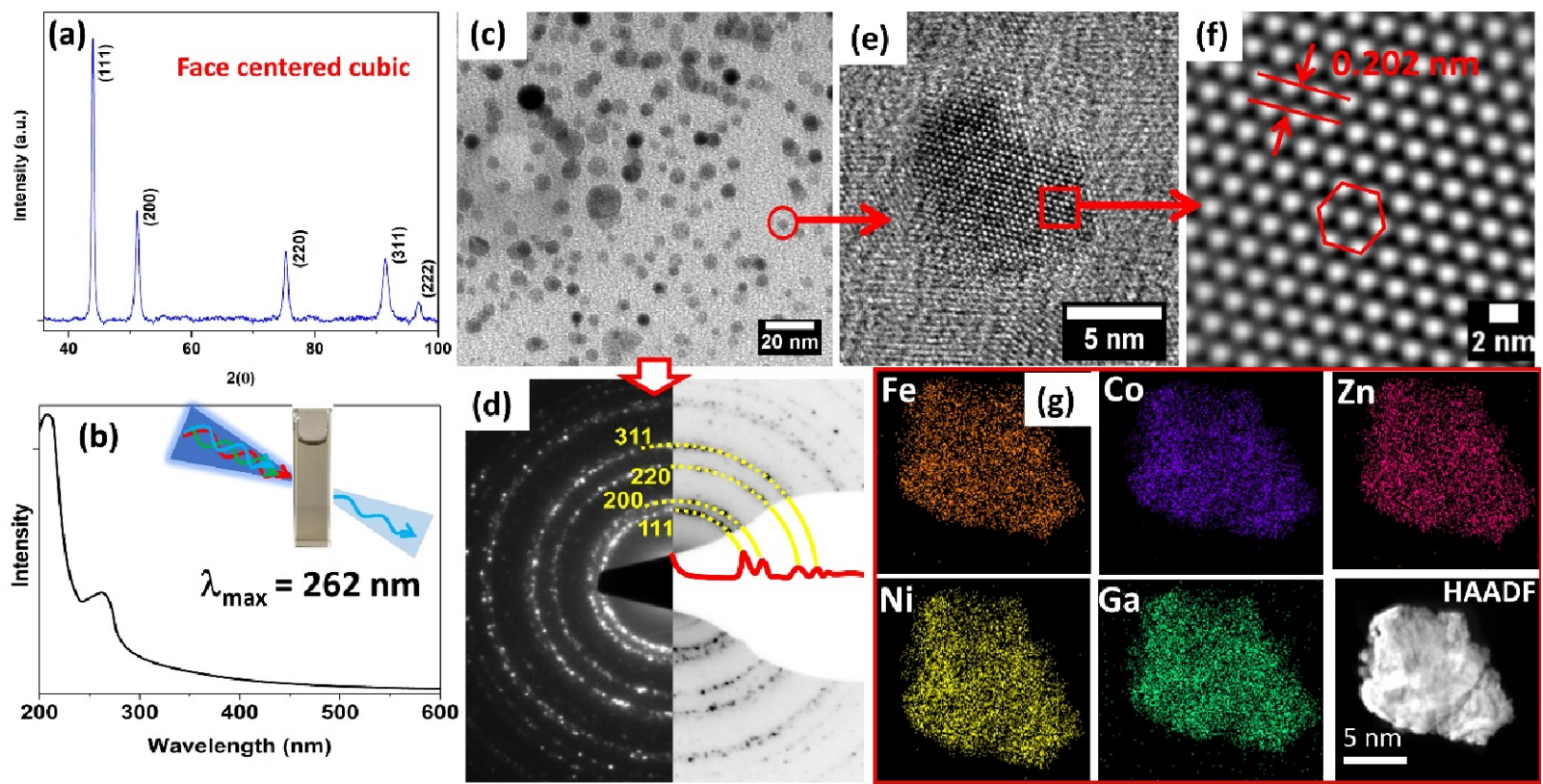

Figure 1: (a) X-ray diffraction pattern of FeCoNiZnGa nanocrystalline powder; (b) Surface plasmon resonance peak of nanoparticles; (c) Bright field (BF) TEM image of HEA (FeCoNiZnGa) nanoparticles (d) corresponding ring diffraction pattern; (e) single nanoparticle HRTEM; (f) FFT filtered image of nanoparticle corresponding to image e; (g) elemental mapping of a single nanoparticle.

X-ray photoelectron spectroscopy (XPS) is an important tool used for surface analysis to obtain the chemical states of the elements ${ }^{32}$. XPS studies were performed for the initial HEA without any treatment, after $\mathrm{CV}$-activation, and after $10 \mathrm{~h}$ of Chronoamperometry studies. XPS wide scan spectra of as prepared FeCoNiZnGa high entropy alloy, after CV activation displayed in Figure S1 shows the presence of all five elements whereas after $10 \mathrm{~h}$ of Chronoamperometry studies only Ga remained at the surface and signal for other elements remained very weak which was not observed with this technique whereas confirmed with the help of TEM in the next section. All the spectra and peak fitting is done by taking the adventitious binding energy of $\mathrm{C} 1 \mathrm{~s}$ at a binding energy of $284.8 \mathrm{eV}$ as reference. $\mathrm{C} 1 \mathrm{~s}$ spectra as shown in Figure 2a deconvoluted in five main peaks. In $\mathrm{C} 1 \mathrm{~s}$ spectrum of as synthesized HEA deconvoluted into three main peaks observed at a binding position of 284.5 $\mathrm{eV}, 286.4 \mathrm{eV}$, and $288.9 \mathrm{eV}$ which is assigned to the functional groups of $\mathrm{C}=\mathrm{C}, \mathrm{C}=\mathrm{O}$ and $\mathrm{O}$ $\mathrm{C}=\mathrm{O}$ respectively. After $\mathrm{CV}$-activation, there is the addition of the one more shake-up transition peak in $\mathrm{C} 1 \mathrm{~s}$ spectra i.e $\mathrm{CO}_{3}{ }^{2-}$ which arises due to ( $\pi$ to $\pi^{*}$ transition $)^{33}$ whose 
intensity reduces upto a great extent after Chronoamperometry. Before OER testing, in as prepared HEA sample $\mathrm{Ni} 2 \mathrm{p}$ spectra confirmed the presence of $\mathrm{Ni}^{0+}\left(\mathrm{Ni}_{2} \mathrm{p}_{3 / 2}, 852.2 \mathrm{eV}\right.$; Ni $2 \mathrm{p}_{1 / 2}, 870.2 \mathrm{eV}$ ) with some oxides at the surface. The oxidation state of the nickel at the surface of the region can be determined by the binding energies and chemical shift in the XPS spectra $^{34}$. However after CV activation, oxides at the surface increases confirmed with the enhanced intensity of $\mathrm{Ni}^{2+}$ peak at binding energy of $855.62 \mathrm{eV}$.
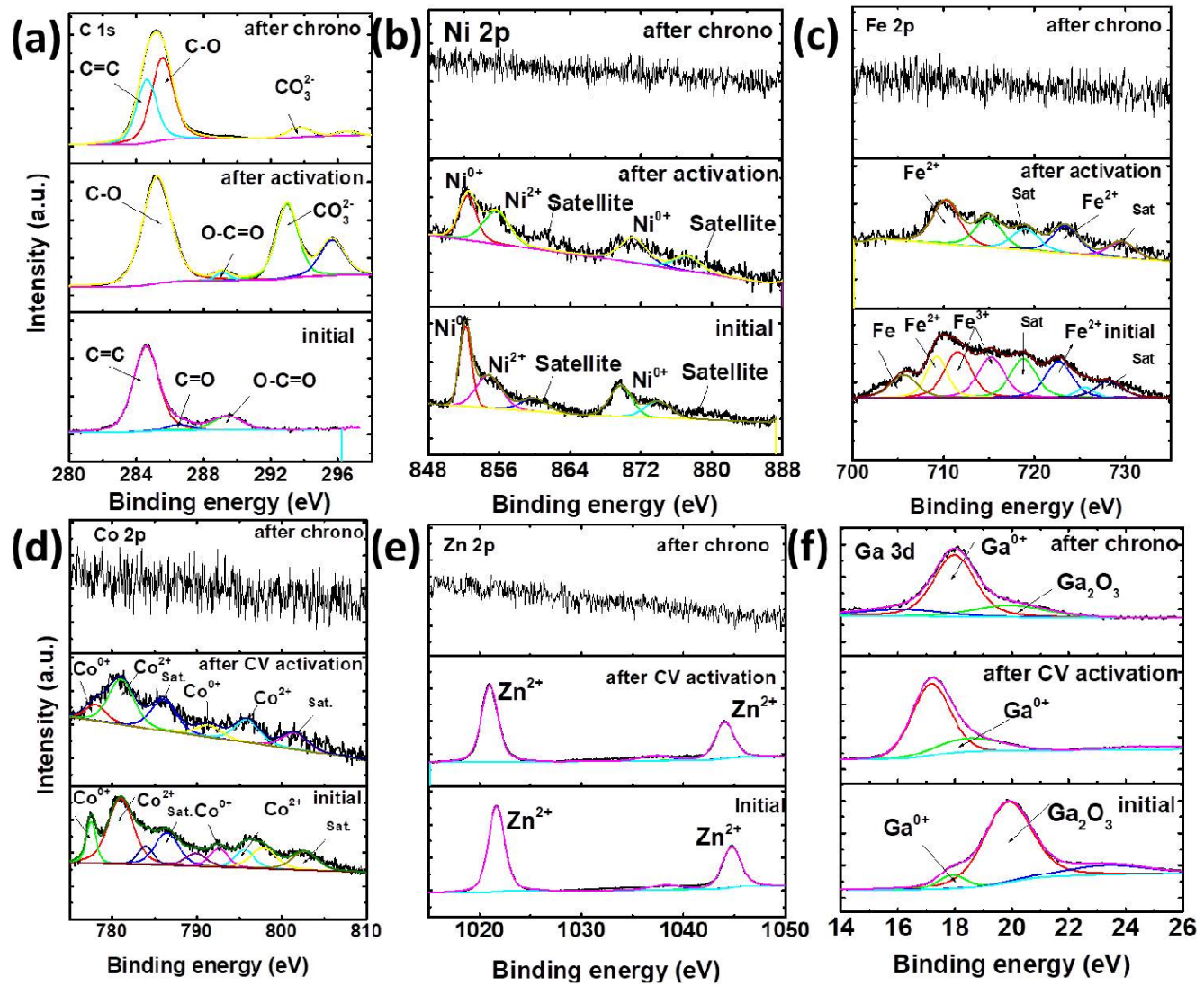

Figure 2: High resolution deconvoluted spectra of (a) C 1s (b) Ni $2 p$ (c) Fe $2 p$ (d) Co $2 p$ (e) $\mathrm{Zn} 2 p$ (f) Ga $3 d$ for initial HEA, after CV activation of 150 cycles and after $10 \mathrm{~h}$ of Chronoamperometry studies in $1 \mathrm{M} \mathrm{KOH}$ electrolyte.

After $\mathrm{CV}$ activation, oxide formation at the surface in the form of $\mathrm{NiO}\left(\mathrm{Ni}^{2+}\right)$ confirmed by XPS contribute towards OER activities. Fe 2p high resolution spectra as shown in Figure 2c displayed that in initial HEA, Fe present in metallic as well as in oxide form whereas, after $\mathrm{CV}$ activation only the oxide form of Fe sustains and after Chronoamperometry of $10 \mathrm{~h}$ signal 
of iron become very weak and no traces of iron have left at the surface as confirmed by XPS spectra. In initial HEA spectra, binding energies obtained at the peak position of $706.7 \mathrm{eV}$ $\left(2 \mathrm{p}_{3 / 2}\right)$ confirmed the $\mathrm{Fe}(0)$ oxidation state. Oxides of Fe after $\mathrm{CV}$ activation was confirmed by characteristic peaks for $\mathrm{Fe}_{2} \mathrm{O}_{3}{ }^{35-36}$ as $\mathrm{Fe} 2 \mathrm{p}_{1 / 2}$ and $\mathrm{Fe} 2 \mathrm{p}_{3 / 2}$ peaks of HEA were centred at peak positions of $723.4 \mathrm{eV}$ and $710.2 \mathrm{eV}$ respectively. Cobalt (Co) in initial HEA as shown in Figure $2 \mathrm{~d}$ found predominantly in the form of Co as metal confirmed by the peak positions at binding energies of $777.5 \mathrm{eV}\left(2 \mathrm{p}_{3 / 2}\right)$ and $792.5 \mathrm{eV}\left(2 \mathrm{p}_{1 / 2}\right)$ respectively. Along with Co as a metallic form, the oxidized form of $\mathrm{Co}$ in the form of $\mathrm{CoO}$ where $\mathrm{Co}$ is in +2 oxidation state was also present, which confirmed by peak positions at binding energies at $781.0 \mathrm{eV}\left(2 \mathrm{p}_{3 / 2}\right)$ and $795.39 \mathrm{eV}\left(2 \mathrm{p}_{1 / 2}\right)^{37}$. Other peak formation at the binding energy positions of $786.4 \mathrm{eV}$, $802.4 \mathrm{eV}$ belongs to the satellite peaks. Two unexplained peaks in the case of Co XPS spectra of initial HEA are still unclear. In the case of XPS spectra of Zn, as shown in Figure 2e, the peaks assigned at binding energies of $1044.8 \mathrm{eV}$ and $1021.80 \mathrm{eV}$ are assigned to the $\mathrm{Zn} 2 \mathrm{p}_{1 / 2}$ and $\mathrm{Zn} 2 \mathrm{p}_{3 / 2}$ peaks of $\mathrm{Zn}^{2+}$ respectively ${ }^{38}$. After $\mathrm{CV}$ activation, there was no change in the oxidation state of $\mathrm{Zn}$. After long term stability test, signal of $\mathrm{Zn}$ become very poor at the surface. XPS spectra of Ga in FeCoNiZnGa has shown a very interesting feature as shown in Figure $2 \mathrm{f}, \mathrm{Ga} 3 \mathrm{~d}$ emission spectra was deconvoluted into two main peaks. Out of two Gaussian peaks, one centred at position of $20.1 \mathrm{eV}$ is expected for the $\mathrm{Ga}(3+)$ oxidation state (stoichiometric $\mathrm{Ga}_{2} \mathrm{O}_{3}$ (Ga III) ${ }^{39-40}$ ), and a second one centred at position of $18.0 \mathrm{eV}$ corresponds to $\mathrm{Ga}(0)$ oxidation state. Ga was present in the form of metallic as well as in the oxide forms at the surface before any $\mathrm{CV}$ activation and contributed more towards OER. One more peak in as synthesised HEA GA 3d spectra at peak position of $23.3 \mathrm{eV}$ associated with the core level contribution of $\mathrm{O} 2 \mathrm{~s} .{ }^{41}$ After long term OER stability testing, testing, Ga is the only element that remained at the surface after $10 \mathrm{~h}$ of stability test in both $\mathrm{Ga}(0)$ as well as Ga (III) oxidation state which played a very important role in enhancing the rate determining 
step involved in OER. Availability of the oxides of Ga at the top of the surface became more feasible after $\mathrm{CV}$ activation as huge enhancement in the OER activities was observed after $\mathrm{CV}$ activation. The formation of the oxides at the surface after $\mathrm{CV}$ activation can be further confirmed with the help of XPS spectra of O 1s in Figure S2 (supporting information). Dual peaks at the peak positions of $529.8 \mathrm{eV}$ and $531.7 \mathrm{eV}$ respectively, in $\mathrm{O} 1 \mathrm{~s}$ indicative of the abundant surface or subsurface oxides and hydroxides. As discussed in the previous literature $^{42-43}$, these oxides/hydroxides at the surface of the electrode help in the fast transport and participating in the OER therein.

\section{Electrochemical Oxygen Evolution Reaction performance (OER)}

Electrochemical oxygen evolution studies of HEA were performed by making catalyst ink, which was decorated at the surface of the glassy carbon electrode and tested for OER in an alkaline medium. Electrochemical OER is 4 -step process in alkaline solution ${ }^{15}$, which can be written as:

$$
\begin{aligned}
& \mathrm{M}^{*}+\mathrm{OH}^{-} \rightarrow \mathrm{MOH}^{*}+e^{-} \\
& \mathrm{MOH}^{*}+\mathrm{OH}^{-} \rightarrow \mathrm{MO}^{*}+\mathrm{H}_{2} \mathrm{O}+e^{-} \\
& \mathrm{MO}^{*}+\mathrm{OH}^{-} \rightarrow \mathrm{MOOH}^{*}+e^{-} \\
& \mathrm{MOOH}^{*}+\mathrm{OH}^{-} \quad \rightarrow \quad \mathrm{M}^{*}+\mathrm{H}_{2} \mathrm{O}+\mathrm{O}_{2}+e^{-}
\end{aligned}
$$

where $*$ represents the active site for the neighbouring species which is $\mathrm{OH}^{-}$in case of alkaline medium and $\mathrm{M}$ is the metallic site which is $\mathrm{Fe}, \mathrm{Co}, \mathrm{Ni}, \mathrm{Zn}$ and $\mathrm{Ga}$ in case of high entropy alloy. Kinetics of OER in case of conventional catalyst is very sluggish ${ }^{7}$ which is due to the involvement of the number of the intermediates involved in the reaction. High entropy alloys are activated before performing the electrochemical testing. The surface of HEA was 
activated by performing $\mathrm{CV}$ cycles in a potential range of $0.5 \mathrm{~V}$ to $1.6 \mathrm{~V}$ vs RHE at a scan rate of $20 \mathrm{mV} / \mathrm{sec}$ until stable cyclic voltammetry $(\mathrm{CV})$ curves were obtained. After completion of the 150 cycles, a stable current CV curve was obtained as shown Figure S3 (supporting information). After the activation process, there was the formation of the more metal oxides and hydroxides at the surface confirmed by the XPS spectra of O 1s (Figure S2). As shown in Figure 3a, LSV curves showed the catalytic activities of HEA electrocatalyst towards OER, which showed overpotential of $370 \mathrm{mV}$ at a current density of $10 \mathrm{~mA} \mathrm{~cm}$. OER testing has also performed for the state of the art catalyst, which is $\mathrm{RuO}_{2}$; which is least active in comparison to $\mathrm{HEA}$. $\mathrm{RuO}_{2}$ showed a very high overpotential of $430 \mathrm{mV}$ at a current density of $10 \mathrm{~mA} \mathrm{~cm}^{-2}$, which is $60 \mathrm{mV}$ high as compare to HEA. In order to further elucidate the mechanism and kinetics behind the OER reaction, Tafel slope has been calculated, as shown in Figure 3b. In the Tafel slopes, a smaller slope indicates the more rapid electron transfer at the electrode/electrolyte interface at the applied potentials, which suggests the better catalytic activity of the electrocatalyst. ${ }^{44}$ Tafel slopes for $\mathrm{HEA}, \mathrm{RuO}_{2}$, after $3000 \mathrm{CV}$ cycles, and after $6000 \mathrm{CV}$ cycles are $71 \mathrm{mV} / \mathrm{dec}, 108 \mathrm{mV} / \mathrm{dec}, 63 \mathrm{mV} / \mathrm{sec}$ and $63 \mathrm{mV} / \mathrm{dec}$ respectively. Tafel plot for HEA was the least as compared to state of the art catalyst $\mathrm{RuO}_{2}$. As discussed in the above section, OER process involved number of reaction intermediates and reaction will become slow if any of the intermediate is in shortage. However, understanding and identification of the rate determining step in case of OER is still an open question. Hence, it is a very elusive way to predict the mechanism only on the basis of Tafel slope. The durability of the electrocatalyst towards OER remained a challenge. Continuous $\mathrm{CV}$ cycling between $1.2 \mathrm{~V}$ to $1.5 \mathrm{~V}$ vs RHE in $1 \mathrm{M} \mathrm{KOH}$ was used to evaluate the durability, as shown in Figure S4 (supporting information). After 6000 cycles of CV cycles, LSV curves are shown in Figure 3a, which shows no difference in the overpotential compared to initial HEA. After 6000 cycles, the Tafel plot was also calculated as shown in Figure 3b, which 

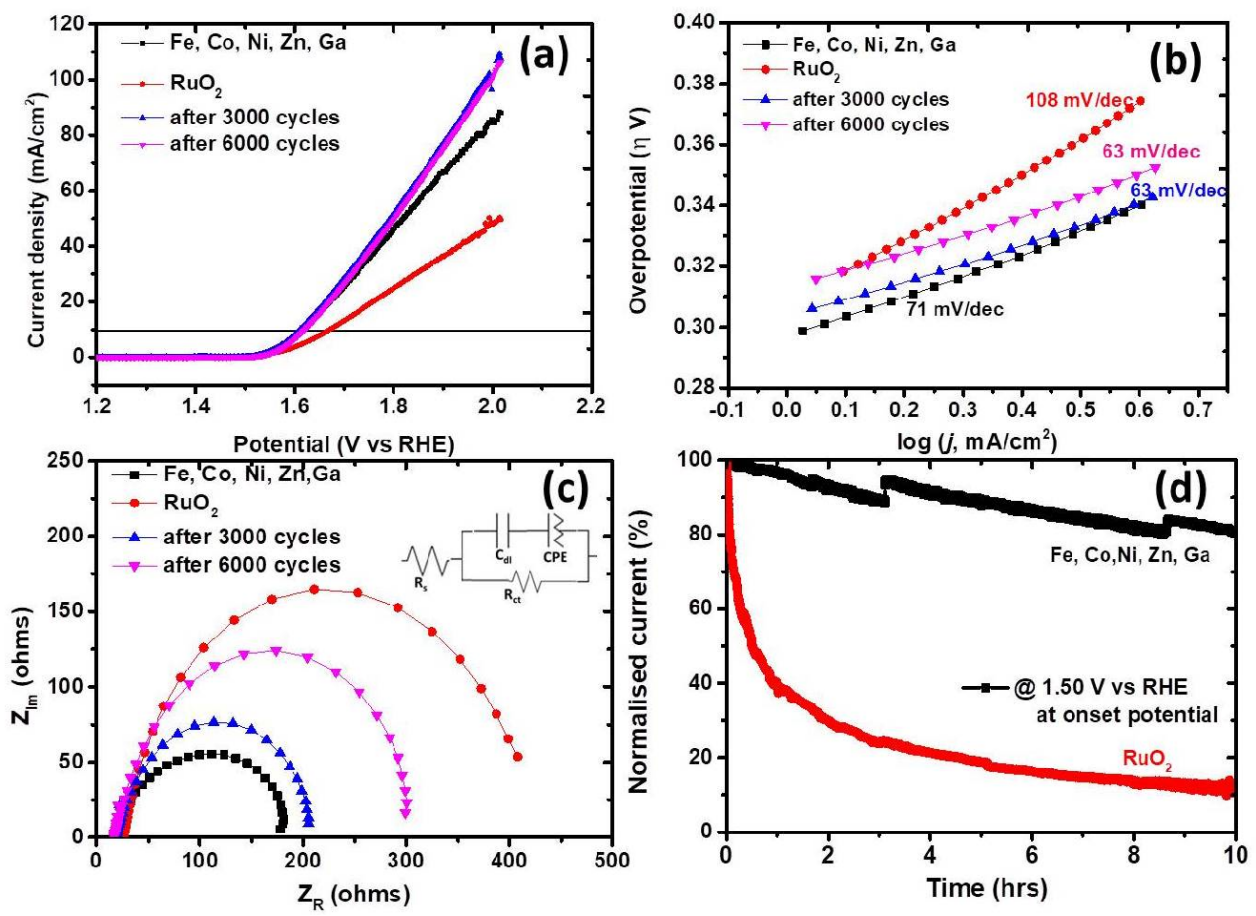

Figure 3: (a) LSV (linear scan voltammetry curves) for oxygen evolution reaction (OER) (b) Tafel plot (c) Nyquist plot for $\mathrm{RuO}_{2}$, initial Fe, Co, Ni, Zn, Ga high entropy alloy (HEA), after 3000 cycles and 6000 cycles of cyclic durability test (d) Chronoamperometry studies for $\mathrm{RuO}_{2}$ and $\mathrm{HEA}$ at operating voltage of $1.5 \mathrm{~V}$ vs RHE in $1 \mathrm{M} \mathrm{KOH}$ electrolyte.

shows $63 \mathrm{mV} / \mathrm{dec}$ confirmed no change in the overall OER performance. These results demonstrated the superior durability of HEA in the alkaline medium. In order to evaluate the charge transfer behaviour at the interface of catalyst/electrolyte interface, electrochemical impedance spectroscopy (EIS) was also performed. EIS is very strong tool to investigate the charge transport behaviour at the interface of electrode/electrolyte. ${ }^{45}$ Nyquist plot at the operating voltage of $1.5 \mathrm{~V}$ vs RHE was displayed in Figure 3c for $\mathrm{HEA}, \mathrm{RuO}_{2}$, after 3000 and 6000 CV cycles. Randle`s Equivalent circuit elements were fitted in NOVA software confirming the $[\mathrm{R}([\mathrm{CQ}] \mathrm{R})]$ Randles` equivalent circuit, as shown in the inset of Figure 3c. 
Table1: OER performance parameters of high entropy alloy in $1 \mathrm{M} \mathrm{KOH}$ electrolyte.

\begin{tabular}{|l|l|l|l|l|l|}
\hline Sample & & $\begin{array}{l}\text { Overpotential } \\
(\eta) @ 10 \mathrm{~mA} \\
\mathrm{~cm}^{-2}\end{array}$ & $\begin{array}{l}\text { Tafel slope } \\
(\mathrm{mV} / \mathrm{dec})\end{array}$ & $\begin{array}{l}\text { Charge } \\
\text { transfer } \\
\text { resistance } \\
\left(\mathrm{R}_{\mathrm{ct}}\right)\end{array}$ & $\begin{array}{l}\text { Solution } \\
\text { resistance } \\
\left(\mathrm{R}_{\mathrm{s}}\right)\end{array}$ \\
\hline FeCoNiZnGa & $0.370 \mathrm{~V}$ & 71 & $166.90 \Omega$ & $17.87 \Omega$ \\
\hline $\mathrm{RuO}_{2}$ & $0.430 \mathrm{~V}$ & 108 & $400.27 \Omega$ & $25.83 \Omega$ \\
\hline $\begin{array}{l}\text { After } 3000 \\
\mathrm{CV} \text { cycles }\end{array}$ & $0.370 \mathrm{~V}$ & 63 & $190.42 \Omega$ & $17.71 \Omega$ \\
\hline $\begin{array}{l}\text { After } 6000 \\
\mathrm{CV} \text { cycles }\end{array}$ & $0.380 \mathrm{~V}$ & 63 & $288.95 \Omega$ & $17.49 \Omega$ \\
\hline
\end{tabular}

HEA forms a very small semicircle of Nyquist plot which suggests the lower charge transfer resistance $\left(\mathrm{R}_{\mathrm{ct}}\right)$ in comparison to $\mathrm{RuO}_{2}$ and after durability testing. All Nyquist curves originated from one point confirmed constant solution resistance $\left(\mathrm{R}_{\mathrm{s}}\right)$, which remains unchanged, and $[\mathrm{R}]$ of the circuit shows the solution resistance. At the interface, there was the formation of a double layer at interface contributed (C) of the equivalent circuit. Overall fitting of the circuit for HEA showed the least charge transfer resistance $\left(\mathrm{R}_{\mathrm{ct}}\right)$ with excellent electron transfer subsequently showed excellent electrochemical activities. The solution resistance $\left(R_{s}\right)$ is the combination of the resistance offered by the solution as well as the contact resistance between the electrode and current collector. ${ }^{46}$ Whereas, semicircle in the Nyquist plot corresponds to the resistance at the HEA/electrolyte interface so called charge transfer resistance $\left(\mathrm{R}_{\mathrm{ct}}\right)$ which was tabulated in Table1. In case of initial HEA which was recorded after $\mathrm{CV}$ activation has very less $\mathrm{R}_{\mathrm{ct}}$ of $166.9 \Omega$ in comparison to state of art $\mathrm{RuO}_{2}$ catalyst. EIS data is in good agreement with the LSV curves as it fully supporting the OER performance. The stability of the FeCoNiZnGa HEA electrocatalyst was evaluated by the Chronoamperometry at a potential of $1.5 \mathrm{~V}$ vs RHE for $10 \mathrm{~h}$. Figure $3 \mathrm{~d}$ showed the 
Chronoamperometry curve of $\mathrm{HEA}$ as well as $\mathrm{RuO}_{2}$ up to $10 \mathrm{~h}$. After completing $10 \mathrm{~h}$ of stability test, FeCoNiZnGa HEA has $80 \%$ current retention and very little degradation of the material. Whereas in the case of $\mathrm{RuO}_{2}$, only $30 \%$ of material retained after completion of 10 $\mathrm{h}$ with a maximum loss of the material up to initial $4 \mathrm{~h}$. The Chronoamperometry test showed tremendous stability of the material with retained OER activities even after $10 \mathrm{~h}$. As shown in Figure S5.a (supporting information), there was almost negligible change in OER performance of HEA after $10 \mathrm{~h}$ of stability test. The Nyquist plot in Figure S5.b after stability also performed at operating voltage of $1.5 \mathrm{~V}$ confirmed very small change in the in the charge transfer resistance of HEA. Furthermore, TEM was also performed to find out the changes occurred in the material after $10 \mathrm{~h}$ of long term of chronoamperometry testing.

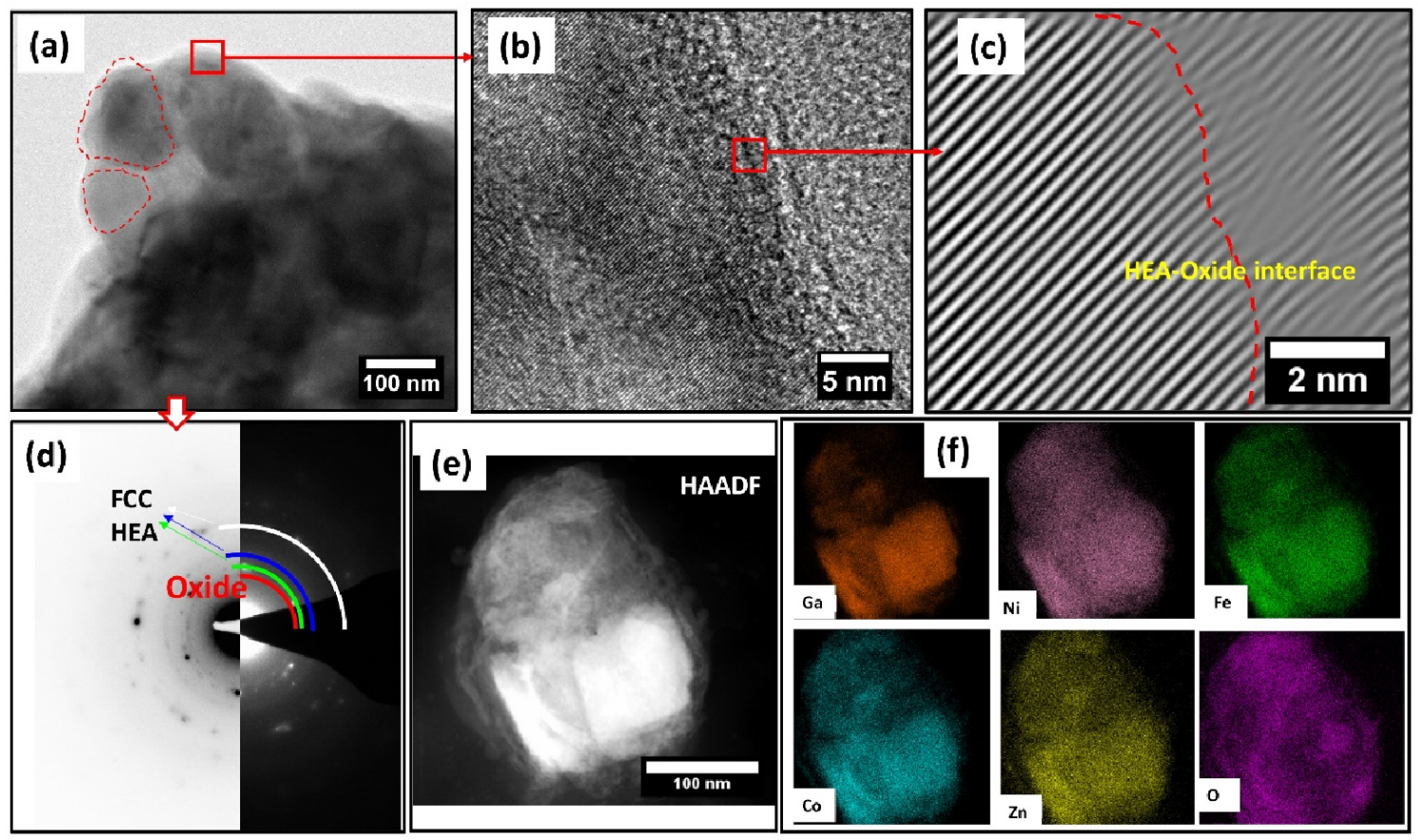

Figure 4: FeCoNiZnGa alloy NPs after $10 \mathrm{~h}$ of chronoamperometry testing (a) bright-field TEM image (b) HRTEM image of NP (c) FFT filtered image of b (d) selected area ring diffraction pattern (e) high angle annular dark (HAADF) field image of a nanoparticles (f) elemental mapping of the nanoparticles.

After chronoamperometry, the alloy nanoparticles were characterized using TEM. The nanoparticles coarsened after $10 \mathrm{~h}$ test; it might be due to oxidation of alloy particles, which 
are getting oxidized due to exposure in the electrolyte. The high-resolution image in Figure 4 b\&c confirmed the oxide formation as d-spacing increasing compare to the as-prepared HRTEM image of nanoparticles. In addition, the ring diffraction pattern of nanoparticles reveals the existence of oxide but still FCC alloy present. However, it is not distinguished about different metallic oxides. The elemental mapping of the NPs reveals homogeneity along with the Oxygen content, as shown in Figure 4f, which was absent before chronoamperometry with electrolyte. Similar results were observed in XPS but don't reveal the existence of as-prepared alloy composition as rather oxides due to surface sensitive techniques and give information from a few atomic layers. These finding support the view that the multicomponent high entropy alloy containing low cost $\mathrm{Fe}, \mathrm{Co}, \mathrm{Ni}, \mathrm{Zn}$ and $\mathrm{Ga}$ elements is excellent OER catalyst with the formation of metallic oxide as the active component with great significance towards the stability of FeCoNiZn Ga based HEA.

\section{Conclusion}

In summary, we have proposed a cost-effective, easy scalable nanocrystalline HEA materials preparation recipe. By electrochemical $\mathrm{CV}$ activation, there is the formation of metallic oxides after scans which significantly improved OER activity. After CV activation, FeCoNiZnGa HEA working electrode achieves overpotential of $370 \mathrm{mV}$ at the current density of $10 \mathrm{~mA} \mathrm{~cm}^{-2}$, as well as the Tafel slope of $71 \mathrm{mV} / \mathrm{dec}$ respectively. It exhibit an outstanding durability of up to 6000 cycles as well as $10 \mathrm{~h}$ stability with no overall change in the OER performance. Besides, providing a new high performance high entropy based OER electrocatalyst, this study will certainly broaden the application of high entropy alloy. 


\title{
AUTHOR INFORMATION
}

\author{
*Corresponding Authors
}

\section{Chandra.tiwary@metal.iitkgp.ac.in,kbiswas@iitk.ac.in, aditi@,iitmandi.ac.in}

\section{Notes}

The authors declare no competing financial interest.

\section{ACKNOWLEDGMENTS}

The authors would like to thanks SERB-DST for funding to carry out this research. We would also like to thank the Imaging centre facilities at the Indian Institute of Technology Kanpur for TEM imaging. We acknowledge Advanced Materials Research Centre (AMRC), IIT Mandi to provide the sophisticated instrumentation facilities.

\section{References}

1. $\quad$ Dresselhaus, M.; Thomas, I., Alternative energy technologies. Nature 2001, 414 (6861), $332-$ 337.

2. Tahir, M.; Pan, L.; Idrees, F.; Zhang, X.; Wang, L.; Zou, J.-J.; Wang, Z. L., Electrocatalytic oxygen evolution reaction for energy conversion and storage: A comprehensive review. Nano Energy 2017, 37, 136-157.

3. Zhang, G.; Yuan, J.; Liu, Y.; Lu, W.; Fu, N.; Li, W.; Huang, H., Boosting the oxygen evolution reaction in non-precious catalysts by structural and electronic engineering. Journal of Materials Chemistry A 2018, 6 (22), 10253-10263.

4. Chen, L.; Dong, X.; Wang, Y.; Xia, Y., Separating hydrogen and oxygen evolution in alkaline water electrolysis using nickel hydroxide. Nature communications 2016, 7 (1), 1-8.

5. McCrory, C. C.; Jung, S.; Peters, J. C.; Jaramillo, T. F., Benchmarking heterogeneous electrocatalysts for the oxygen evolution reaction. Journal of the American Chemical Society 2013, 135 (45), 16977-16987.

6. Dai, W.; Lu, T.; Pan, Y., Novel and promising electrocatalyst for oxygen evolution reaction based on MnFeCoNi high entropy alloy. Journal of Power Sources 2019, 430, 104-111.

7. Doyle, R. L.; Lyons, M. E., The oxygen evolution reaction: mechanistic concepts and catalyst design. In Photoelectrochemical solar fuel production, Springer: 2016; pp 41-104.

8. Lee, Y.; Suntivich, J.; May, K. J.; Perry, E. E.; Shao-Horn, Y., Synthesis and activities of rutile IrO2 and RuO2 nanoparticles for oxygen evolution in acid and alkaline solutions. The journal of physical chemistry letters 2012, 3 (3), 399-404.

9. Lu, F.; Zhou, M.; Zhou, Y.; Zeng, X., First-row transition metal based catalysts for the oxygen evolution reaction under alkaline conditions: basic principles and recent advances. Small 2017, 13 (45), 1701931.

10. Jiang, J.; Liu, Q.; Zeng, C.; Ai, L., Cobalt/molybdenum carbide@ N-doped carbon as a bifunctional electrocatalyst for hydrogen and oxygen evolution reactions. Journal of Materials Chemistry A 2017, 5 (32), 16929-16935. 
11. Li, H.; Wen, P.; Li, Q.; Dun, C.; Xing, J.; Lu, C.; Adhikari, S.; Jiang, L.; Carroll, D. L.; Geyer, S. M., Earth-abundant iron diboride (FeB2) nanoparticles as highly active bifunctional electrocatalysts for overall water splitting. Advanced Energy Materials 2017, 7 (17), 1700513.

12. Dong, B.; Zhao, X.; Han, G.-Q.; Li, X.; Shang, X.; Liu, Y.-R.; Hu, W.-H.; Chai, Y.-M.; Zhao, H.; Liu, C.-G., Two-step synthesis of binary $\mathrm{Ni}$-Fe sulfides supported on nickel foam as highly efficient electrocatalysts for the oxygen evolution reaction. Journal of Materials Chemistry A 2016, 4 (35), 13499-13508.

13. Yagi, M.; Kaneko, M., Molecular catalysts for water oxidation. Chemical Reviews 2001, 101 (1), 21-36.

14. Ma, P.; Zhang, S.; Zhang, M.; Gu, J.; Zhang, L.; Sun, Y.; Ji, W.; Fu, Z., Hydroxylated highentropy alloy as highly efficient catalyst for electrochemical oxygen evolution reaction. Science China Materials 2020, 1-7.

15. Ding, Z.; Bian, J.; Shuang, S.; Liu, X.; Hu, Y.; Sun, C.; Yang, Y., High Entropy Intermetallic-Oxide Core-Shell Nanostructure as Superb Oxygen Evolution Reaction Catalyst. Advanced Sustainable Systems 2020, 4 (5), 1900105.

16. Batchelor, T. A. A.; Pedersen, J. K.; Winther, S. H.; Castelli, I. E.; Jacobsen, K. W.; Rossmeisl, J., High-Entropy Alloys as a Discovery Platform for Electrocatalysis. Joule 2019, 3 (3), 834-845.

17. Cantor, B., Multicomponent and high entropy alloys. Entropy 2014, 16 (9), 4749-4768.

18. Ye, Y. F.; Wang, Q.; Lu, J.; Liu, C. T.; Yang, Y., High-entropy alloy: challenges and prospects. Mater. Today 2016, 19 (6), 349-362.

19. Katiyar, N. K.; Nellaiappan, S.; Kumar, R.; Malviya, K. D.; Pradeep, K.; Singh, A. K.; Sharma, S.; Tiwary, C. S.; Biswas, K., Formic acid and methanol electro-oxidation and counter hydrogen production using nano high entropy catalyst. Materials Today Energy 2020, 16, 100393.

20. Xie, P.; Yao, Y.; Huang, Z.; Liu, Z.; Zhang, J.; Li, T.; Wang, G.; Shahbazian-Yassar, R.; Hu, L.; Wang, C., Highly efficient decomposition of ammonia using high-entropy alloy catalysts. Nature communications 2019, 10 (1), 1-12.

21. Huang, K.; Zhang, B.; Wu, J.; Zhang, T.; Peng, D.; Cao, X.; Zhang, Z.; Li, Z.; Huang, Y., Exploring the impact of atomic lattice deformation on oxygen evolution reactions based on a sub- $5 \mathrm{~nm}$ pure face-centred cubic high-entropy alloy electrocatalyst. Journal of Materials Chemistry A 2020.

22. Chen, D.; Chen, C.; Baiyee, Z. M.; Shao, Z.; Ciucci, F., Nonstoichiometric Oxides as Low-Cost and Highly-Efficient Oxygen Reduction/Evolution Catalysts for Low-Temperature Electrochemical Devices. Chemical Reviews 2015, 115 (18), 9869-9921.

23. Nellaiappan, S.; Katiyar, N. K.; Kumar, R.; Parui, A.; Malviya, K. D.; Pradeep, K.; Singh, A. K.; Sharma, S.; Tiwary, C. S.; Biswas, K., High-entropy alloys as catalysts for the $\mathrm{CO} 2$ and $\mathrm{CO}$ reduction reactions: experimental realization. ACS Catalysis 2020, 10 (6), 3658-3663.

24. Zhang, G.; Ming, K.; Kang, J.; Huang, Q.; Zhang, Z.; Zheng, X.; Bi, X., High entropy alloy as a highly active and stable electrocatalyst for hydrogen evolution reaction. Electrochimica Acta 2018, $279,19-23$.

25. Zhang, Y.; Zuo, T. T.; Tang, Z.; Gao, M. C.; Dahmen, K. A.; Liaw, P. K.; Lu, Z. P., Microstructures and properties of high-entropy alloys. Progress in Materials Science 2014, 61, 1-93.

26. Katiyar, N. K.; Nellaiappan, S.; Kumar, R.; Malviya, K. D.; Pradeep, K. G.; Singh, A. K.; Sharma, S.; Tiwary, C. S.; Biswas, K., Formic acid and methanol electro-oxidation and counter hydrogen production using nano high entropy catalyst. Mater. Today Energy 2020, 16, 100393.

27. Nellaiappan, S.; Katiyar, N. K.; Kumar, R.; Parui, A.; Malviya, K. D.; Pradeep, K. G.; Singh, A. K.; Sharma, S.; Tiwary, C. S.; Biswas, K., High-Entropy Alloys as Catalysts for the $\mathrm{CO}_{2}$ and $\mathrm{CO}$ Reduction Reactions: Experimental Realization. ACS Catalysis 2020, 10 (6), 3658-3663.

28. Urs, K. M. B.; Katiyar, N. K.; Kumar, R.; Biswas, K.; Singh, A. K.; Tiwary, C. S.; Kamble, V., Multi-component (Ag-Au-Cu-Pd-Pt) alloy nanoparticle-decorated p-type 2D-molybdenum disulfide (MoS2) for enhanced hydrogen sensing. Nanoscale 2020, 12 (22), 11830-11841.

29. Kumar, N.; Tiwary, C. S.; Biswas, K., Preparation of nanocrystalline high-entropy alloys via cryomilling of cast ingots. J. mater. Sci. 2018, 53 (19), 13411-13423. 
30. Katiyar, N. K.; Biswas, K.; Tiwary, C. S.; Machado, L. D.; Gupta, R. K., Stabilization of a Highly Concentrated Colloidal Suspension of Pristine Metallic Nanoparticles. Langmuir 2019, 35 (7), 26682673.

31. Kumar, N.; Biswas, K.; Gupta, R. K., Green synthesis of Ag nanoparticles in large quantity by cryomilling. RSC Advances 2016, 6 (112), 111380-111388.

32. Seah, M., The quantitative analysis of surfaces by XPS: a review. Surface and Interface Analysis 1980, 2 (6), 222-239.

33. Pelegov, D. V.; Koshkina, A. A.; Pryakhina, V. I.; Gorshkov, V. S., Efficiency threshold of carbon layer growth in Li4Ti5O12/C composites. Journal of The Electrochemical Society 2018, 166 (3), A5019.

34. Grosvenor, A. P.; Biesinger, M. C.; Smart, R. S. C.; McIntyre, N. S., New interpretations of XPS spectra of nickel metal and oxides. Surface Science 2006, 600 (9), 1771-1779.

35. Fujii, T.; De Groot, F.; Sawatzky, G.; Voogt, F.; Hibma, T.; Okada, K., In situ XPS analysis of various iron oxide films grown by NO 2-assisted molecular-beam epitaxy. Physical review B 1999, 59 (4), 3195.

36. Lv, H.; Zhao, H.; Cao, T.; Qian, L.; Wang, Y.; Zhao, G., Efficient degradation of high concentration azo-dye wastewater by heterogeneous Fenton process with iron-based metal-organic framework. Journal of Molecular Catalysis A: Chemical 2015, 400, 81-89.

37. Tan, B. J.; Klabunde, K. J.; Sherwood, P. M., XPS studies of solvated metal atom dispersed (SMAD) catalysts. Evidence for layered cobalt-manganese particles on alumina and silica. Journal of the American Chemical Society 1991, 113 (3), 855-861.

38. Du, X.; Zhao, H.; Lu, Y.; Zhang, Z.; Kulka, A.; Świerczek, K., Synthesis of core-shell-like ZnS/C nanocomposite as improved anode material for lithium ion batteries. Electrochimica Acta 2017, 228, 100-106.

39. Carli, R.; Bianchi, C., XPS analysis of gallium oxides. Applied surface science 1994, 74 (1), 99 102.

40. Bourque, J. L.; Biesinger, M. C.; Baines, K. M., Chemical state determination of molecular gallium compounds using XPS. Dalton Transactions 2016, 45 (18), 7678-7696.

41. Petitmangin, A.; Gallas, B.; Hebert, C.; Perriere, J.; Binet, L.; Barboux, P.; Portier, X., Characterization of oxygen deficient gallium oxide films grown by PLD. Applied surface science 2013, 278, 153-157.

42. Hardin, W. G.; Mefford, J. T.; Slanac, D. A.; Patel, B. B.; Wang, X.; Dai, S.; Zhao, X.; Ruoff, R. S.; Johnston, K. P.; Stevenson, K. J., Tuning the electrocatalytic activity of perovskites through active site variation and support interactions. Chemistry of Materials 2014, 26 (11), 3368-3376.

43. Hardin, W. G.; Slanac, D. A.; Wang, X.; Dai, S.; Johnston, K. P.; Stevenson, K. J., Highly active, nonprecious metal perovskite electrocatalysts for bifunctional metal-air battery electrodes. The journal of physical chemistry letters 2013, 4 (8), 1254-1259.

44. Fabbri, E.; Habereder, A.; Waltar, K.; Kötz, R.; Schmidt, T. J., Developments and perspectives of oxide-based catalysts for the oxygen evolution reaction. Catalysis Science \& Technology 2014, 4 (11), 3800-3821.

45. Orazem, M. E.; Pébère, N.; Tribollet, B., Enhanced graphical representation of electrochemical impedance data. Journal of The Electrochemical Society 2006, 153 (4), B129.

46. Mei, B.-A.; Munteshari, O.; Lau, J.; Dunn, B.; Pilon, L., Physical interpretations of Nyquist plots for EDLC electrodes and devices. The Journal of Physical Chemistry C 2018, 122 (1), 194-206. 